\title{
Mortality rate of acute kidney injury in SARS, MERS, and COVID-19 infection: a systematic review and meta-analysis
}

\author{
Yih-Ting Chen ${ }^{1,2 \dagger}$, Shih-Chieh Shao ${ }^{3,4 \dagger}$, Edward Chia-Cheng Lai ${ }^{3}$, Ming-Jui Hung ${ }^{5,6}$ and Yung-Chang Chen ${ }^{1,7,8,9^{*}}$
}

Keywords: Acute kidney injury, Mortality, COVID-19, MERS, SARS

Acute kidney injury (AKI), a predictor for poor clinical outcomes, has been reported as a severe complication of different coronavirus infections, including novel coronavirus disease 2019 (COVID-19) [1]. COVID-19 is considered more contagious than previous coronavirus infections, e.g., severe acute respiratory syndrome (SARS) and Middle East respiratory syndrome (MERS) [2], but comparisons of mortality rates from AKI among these three coronavirus infections remain uninvestigated. We therefore conducted a systematic review and meta-analysis comparing the mortality rate in patients with SARS, MERS, and COVID-19 who developed AKI.

A systematic search of PUBMED and EMBASE from inception to June 5, 2020, included the keywords "coronavirus", "COVID-19", "MERS", "SARS", "acute kidney injury", "prognosis", and "mortality" with suitable MeSH terms to identify observational studies of relevance, e.g., case reports, case series, cross-sectional studies, and cohort studies. Reference lists of included, published, systematic reviews identified in the search were screened for additional studies. We excluded conference abstracts, review articles, or studies without reports of AKI mortality. Two reviewers (YTC, SCS) screened titles and abstracts of search results for relevance and individually

\footnotetext{
* Correspondence: cyc2356@gmail.com

${ }^{\dagger}$ Yih-Ting Chen and Shih-Chieh Shao contributed equally to this work.

'Department of Nephrology, Department of Internal Medicine, Keelung Chang Gung Memorial Hospital, Keelung, Taiwan

${ }^{7}$ Kidney Research Center, Department of Nephrology, Linkou Chang Gung Memorial Hospital, Taoyuan, Taiwan

Full list of author information is available at the end of the article
}

and independently assessed the full texts of selected results. The final list of included studies was derived by discussion and unanimous agreement from both authors. Statistical analyses were performed using MedCalc for Windows, version 15.0 (MedCalc Software, Ostend, Belgium). We report the mortality rate from AKI in SARS, MERS, and COVID-19 infections as proportions with $95 \%$ confidence interval (CI) based on random effects model, represented by forest plot. We detected heterogeneity among studies using the Cochran Q test, with $p$ value $<0.10$ indicating significant heterogeneity, and calculated $I^{2}$ statistic to determine the proportion of total variation in study estimates attributable to heterogeneity.

After screening 97 records in total, we excluded 74 articles (15 duplicates, 11 irrelevant to study question, 1 conference abstract, 5 review articles and 42 lacking data on AKI mortality). Our final analysis included 23 articles comprising 4, 3 and 16 on SARS, MERS and COVID-19 infection, respectively. Demographic data for included articles are presented in Table 1. Overall, mortality in patients with SARS, MERS and COVID-19 infection, and developing AKI, was 77.4\% (95\%CI: 64.7-88.0). We found the mortality rate of AKI was highest in SARS (86.6\%; 95\%CI: 77.7-93.5), followed by COVID-19 (76.5\%; 95\%CI: $61.0-89.0)$ and MERS (68.5\%; 95\%CI: 53.8-81.5). There was no evidence of statistical heterogeneity among studies reporting AKI mortality in SARS (I2: $0.0 \%, p=0.589$ ) and MERS (I2: $0.0 \%, p=\mathrm{v} 0.758)$, but there was for COVID-19 infection (I2: 97.0\%, $p<0.001$ ) (Fig. 1). 
Table 1 Study characteristics

\begin{tabular}{|c|c|c|c|c|c|c|c|c|c|c|}
\hline Author and year & Country/city & AKI male (\%) & $\begin{array}{l}\text { AKI age } \\
\text { (median) }\end{array}$ & Settings & $\begin{array}{l}\text { Total case } \\
\text { numbers }\end{array}$ & $\begin{array}{l}\text { AKI case } \\
\text { numbers }\end{array}$ & $\begin{array}{l}\text { Baseline serum } \\
\text { creatinine } \\
\text { (mg/dL) }\end{array}$ & $\begin{array}{l}\text { RRT/AKI } \\
\text { case (\%) }\end{array}$ & $\begin{array}{l}\text { AKI } \\
\text { mortality } \\
(\%)\end{array}$ & $\begin{array}{l}\text { Overall } \\
\text { mortality } \\
(\%) \\
\end{array}$ \\
\hline \multicolumn{11}{|l|}{ SARS } \\
\hline Huang 2005 [3] & Taiwan/Taipei & 77 & $65^{*}$ & Hospitalization & 78 & 13 & 1.20 & 38 & 77 & 19 \\
\hline Wu 2004 [4] & Taiwan/Taipei & 50 & $58^{*}$ & Hospitalization & 2 & 2 & 1.05 & NA & 100 & 100 \\
\hline Chu 2005 [5] & China/Hong Kong & 69 & 54 & Hospitalization & 536 & 36 & 1.06 & 28 & 92 & 14 \\
\hline Choi 2003 [6] & China/Hong Kong & NA & NA & Hospitalization & 267 & 15 & NA & NA & 87 & 12 \\
\hline \multicolumn{11}{|l|}{ MERS } \\
\hline Saad 2014 [7] & Saudi Arabia & NA & NA & Hospitalization & 70 & 30 & NA & NA & 70 & 60 \\
\hline Alsaad 2017 [8] & Saudi Arabia & 100 & 33 & Intensive care unit & 1 & 1 & NA & 0 & 100 & 100 \\
\hline Cha 2015 [9] & Korea & 63 & $73^{*}$ & Hospitalization & 30 & 8 & 1.60 & 38 & 63 & 17 \\
\hline \multicolumn{11}{|l|}{ COVID-19 } \\
\hline Alberici 2020 [10] & Italy/Brescia & 67 & $58^{*}$ & $\begin{array}{l}\text { Kidney transplantation/ } \\
\text { hospitalization }\end{array}$ & 20 & 6 & 3.13 & 17 & 17 & 25 \\
\hline Hirsch 2020 [11] & USA/New York & 64 & 69 & Hospitalization & 5449 & 1993 & 1.24 & 14 & 35 & 16 \\
\hline Lei 2020 [12] & China/Wuhan & NA & NA & Hospitalization & 34 & 2 & NA & NA & 100 & 21 \\
\hline Chen 2020 [13] & China/Wuhan & NA & NA & Hospitalization & 274 & 29 & NA & 10 & 97 & 41 \\
\hline Deng 2020 [14] & China/Wuhan & NA & NA & Hospitalization & 225 & 20 & NA & NA & 100 & 48 \\
\hline Wang 2020 [15] & China/Wuhan & NA & NA & Hospitalization & 107 & 14 & NA & NA & 100 & 18 \\
\hline Yang 2020 [16] & China/Wuhan & NA & NA & Hospitalization & 52 & 15 & NA & 60 & 80 & 62 \\
\hline Gopalakrishnan 2020 [17] & USA & 100 & 49 & Hospitalization & 1 & 1 & 1.00 & 100 & 100 & 100 \\
\hline Suwanwongse 2020 [18] & USA/New York & 100 & 88 & Hospitalization & 1 & 1 & 1.16 & 0 & 0 & 0 \\
\hline Banerjee 2020 [19] & UK/London & 25 & $59^{*}$ & $\begin{array}{l}\text { Kidney transplantation/ } \\
\text { hospitalization }\end{array}$ & 7 & 4 & 2.54 & 75 & 25 & 14 \\
\hline Zhou 2020 [20] & China/Wuhan & NA & NA & Hospitalization & 191 & 28 & NA & 36 & 96 & 28 \\
\hline Wang 2020 [21] & China/Wuhan & NA & NA & Hospitalization & 339 & 27 & NA & NA & 63 & 19 \\
\hline Richardson 2020 [22] & USA/New York & NA & NA & Hospitalization & 2351 & 523 & NA & 15 & 66 & 20 \\
\hline Wang 2020 [23] & China/Wuhan & NA & NA & Intensive care unit & 344 & 86 & NA & 10 & 93 & 39 \\
\hline Ruan 2020 [24] & China/Wuhan & NA & NA & Hospitalization & 150 & 23 & NA & 22 & 91 & 45 \\
\hline Cao 2020 [25] & China/Wuhan & NA & NA & Hospitalization & 102 & 20 & NA & 30 & 75 & 17 \\
\hline
\end{tabular}

$A K I$ acute kidney injury, NA not available, $R R T$ renal replacement therapy

${ }^{*}$ Age was represented by the mean value

The present analyses indicate AKI as a poor prognosis factor in coronavirus infections, whereby AKI mortality in COVID-19 is higher than MERS but lower than SARS infections. Possible mechanisms of higher AKI mortality following coronavirus infections are multifactorial (e.g., severe sepsis-related multiorgan failure, direct kidney involvement, and acute respiratory distress syndrome) [26-28], although comparative pathogenesis of kidney involvement among the three infections remains unclear.

To our best knowledge, this is the first systematic review exploring AKI mortality of different coronavirus infections. However, we should be cautious about interpreting causal relationships between coronavirus infections and AKI, given the nature of observational data. Also, clinical heterogeneity between studies should be noted; for example, various healthcare systems of included studies may produce different AKI mortality rates. Coronaviruses are unlikely to be eliminated in the near future, and our synthesis indicates that AKI secondary to coronavirus infection may contribute to higher mortality. Hence, in the current exceptional pandemic, first-line healthcare providers should recognize the importance of timely detection of AKI and consider all available treatment options for maintenance of kidney functions to prevent death in COVID-19 patients [29].

\section{Abbreviations}

AKI: Acute kidney injury; Cl: Confidence interval; COVID-19: Coronavirus disease 2019; MERS: Middle East respiratory syndrome; SARS: Severe acute respiratory syndrome

\section{Acknowledgements}

None.

\section{Authors' contributions}

YCY and SCS contributed equally to this work. YCY and SCS contributed to the critical analysis, interpretation of the data, and drafting of the 
(a) SARS

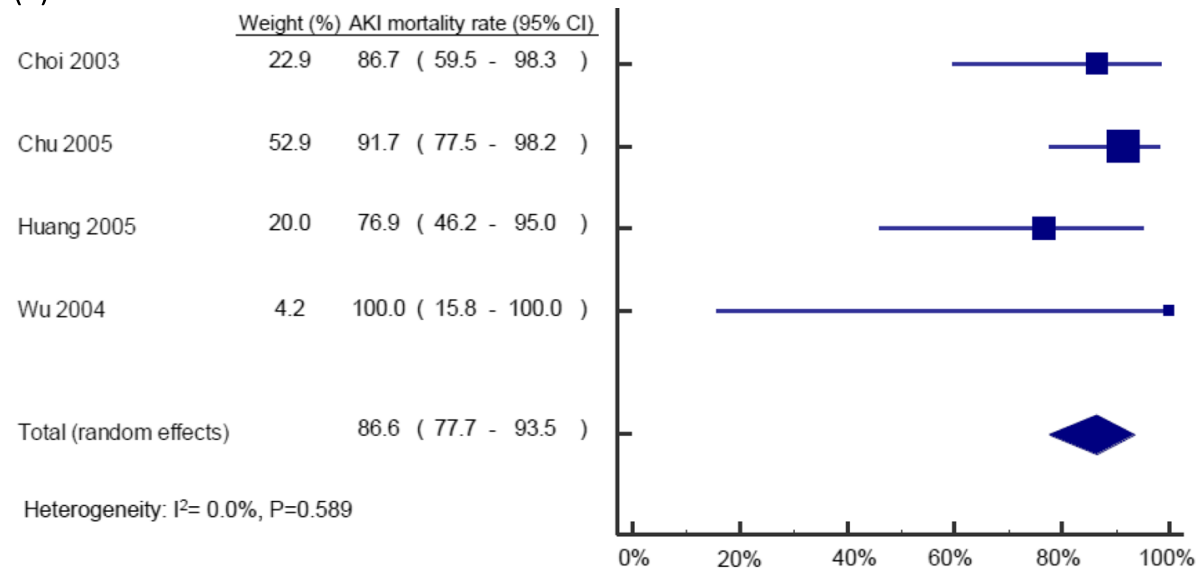

(b) MERS

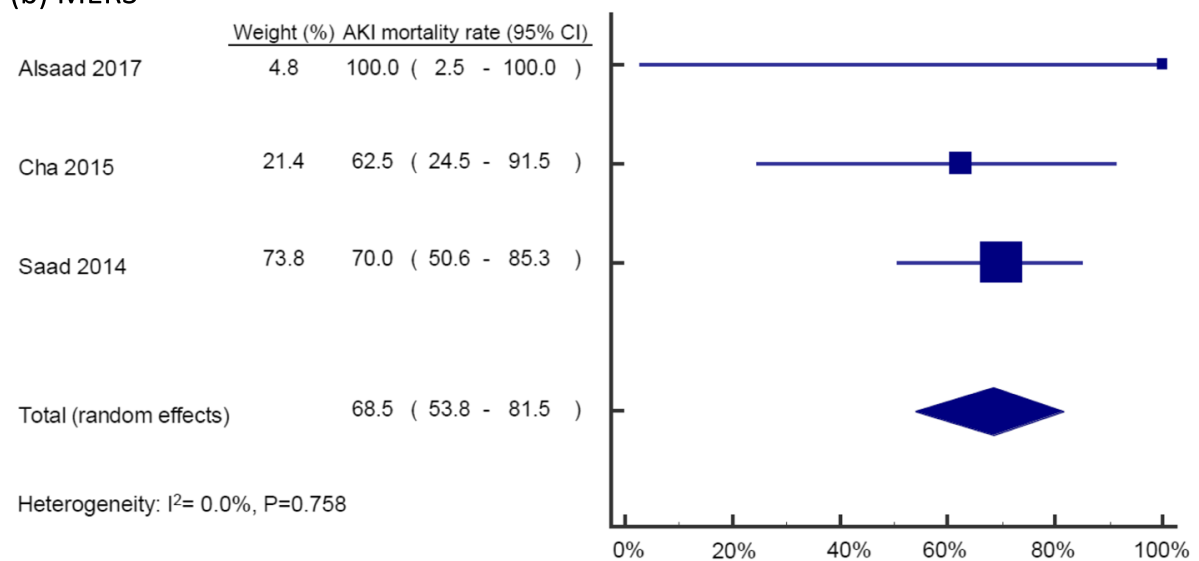

(c) COVID-19

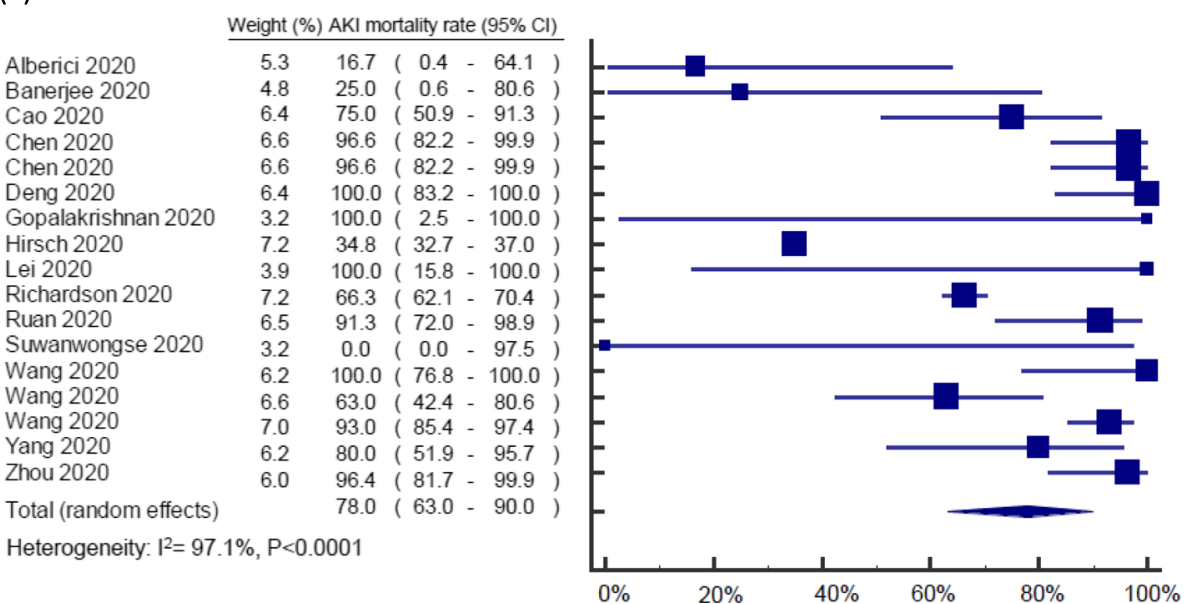

Fig. 1 Forest plot of AKI mortality in coronavirus infections from included studies: a SARS, b MERS, and c COVID-19 
manuscript. MJH and YCC contributed to the study supervision and administrative, technical, or material support. All authors read and approved the final manuscript.

\section{Funding}

None.

\section{Availability of data and materials Not applicable.}

\section{Ethics approval and consent to participate}

Not applicable.

\section{Consent for publication}

This original article has not been published and is not under consideration by another journal.

\section{Competing interests}

None.

\section{Author details}

'Department of Nephrology, Department of Internal Medicine, Keelung Chang Gung Memorial Hospital, Keelung, Taiwan. ${ }^{2}$ Institute of Public Health, School of Medicine, National Yang Ming University, Taipei, Taiwan. ${ }^{3}$ School of Pharmacy, Institute of Clinical Pharmacy and Pharmaceutical Sciences, College of Medicine, National Cheng Kung University, Tainan, Taiwan. ${ }^{4}$ Department of Pharmacy, Keelung Chang Gung Memorial Hospital, Keelung, Taiwan. ${ }^{5}$ College of Medicine, Chang Gung University, Taoyuan, Taiwan. ${ }^{6}$ Section of Cardiology, Department of Internal Medicine, Keelung Chang Gung Memorial Hospital, Keelung, Taiwan. ${ }^{7}$ Kidney Research Center, Department of Nephrology, Linkou Chang Gung Memorial Hospital, Taoyuan, Taiwan. ${ }^{8}$ Community Medicine Research Center, Keelung Chang Gung Memorial Hospital, Keelung, Taiwan. ${ }^{9}$ Division of Nephrology, Department of Medicine, Keelung Chang Gung Memorial Hospital, No. 222, Maijin Rd., Anle Dist., Keelung, Taiwan.

Received: 6 June 2020 Accepted: 1 July 2020

Published online: 16 July 2020

\section{References}

1. Chen Y-T, Shao S-C, Hsu C-K, Wu I-W, Hung M-J, Chen Y-C. Incidence of acute kidney injury in COVID-19 infection: a systematic review and metaanalysis. Critical Care. 2020;24(1):346.

2. Naicker S, Yang CW, Hwang SJ, Liu BC, Chen JH, Jha V. The novel coronavirus 2019 epidemic and kidneys. Kidney Int. 2020;97(5):824-8.

3. Huang JW, Chen KY, Tsai HB, Wu VC, Yang YF, Wu MS, Chu TS, Wu KD. Acute renal failure in patients with severe acute respiratory syndrome. J Formos Med Assoc. 2005:104(12):891-96.

4. Wu VC, Hsueh PR, Lin WC, Huang JW, Tsai HB, Chen YM, Wu KD. SARS Research Group of the National Taiwan University College of Medicine and National University Hospital: Acute renal failure in SARS patients: more than rhabdomyolysis. Nephrol Dial Transplant. 2004;19(12):3180-182.

5. Chu KH, Tsang WK, Tang CS, Lam MF, Lai FM, To KF, Fung KS, Tang HL, Yan WW, Chan HWH, et al. Acute renal impairment in coronavirus-associated severe acute respiratory syndrome. Kidney Int. 2005;67(2):698-705.

6. Choi KW, Chau TN, Tsang O, Tso E, Chiu MC, Tong WL, Lee PO, Ng TK, Ng WF, Lee KC, et al. Outcomes and prognostic factors in 267 patients with severe acute respiratory syndrome in Hong Kong. Ann Intern Med. 2003; 139(9):715-23.

7. Saad M, Omrani AS, Baig K, Bahloul A, Elzein F, Matin MA, Selim MA, Al Mutairi M, Al Nakhli D, Al Aidaroos AY, et al. Clinical aspects and outcomes of 70 patients with Middle East respiratory syndrome coronavirus infection: a single-center experience in Saudi Arabia. Int J Infect Dis. 2014;29:301-06.

8. Alsaad KO, Hajeer AH, Al Balwi M, Al Moaiqel M, Al Oudah N, Al Ajlan A, AlJohani S, Alsolamy S, Gmati GE, Balkhy H, et al: Histopathology of Middle East respiratory syndrome coronovirus (MERS-CoV) infection - clinicopathological and ultrastructural study. Histopathology. 2018;72(3):516-24.

9. Cha RH, Joh JS, Jeong I, Lee JY, Shin HS, Kim G, Kim Y. Critical Care Team of National Medical Center: Renal Complications and Their Prognosis in Korean Patients with Middle East Respiratory Syndrome-Coronavirus from the Central MERS-CoV Designated Hospital. J Korean Med Sci. 2015;30(12):1807-814.
10. Alberici F, Delbarba E, Manenti C, Econimo L, Valerio F, Pola A, Maffei C, Possenti S, Zambetti N, Moscato M, et al: A single center observational study of the clinical characteristics and short-term outcome of 20 kidney transplant patients admitted for SARS-CoV2 pneumonia. Kidney Int. 2020; 97(6):1083-88

11. Hirsch JS, Ng JH, Ross DW, Sharma P, Shah HH, Barnett RL, Hazzan AD, Fishbane S, Jhaveri KD. Acute kidney injury in patients hospitalized with COVID-19. Kidney Int. 2020;98(1):209-18.

12. Lei S, Jiang F, Su W, Chen C, Chen J, Mei W, Zhan LY, Jia Y, Zhang L, Liu D, et al. Clinical characteristics and outcomes of patients undergoing surgeries during the incubation period of COVID-19 infection. E Clinical Medicine. 2020;23:100385

13. Chen T, Wu D, Chen H, Yan W, Yang D, Chen G, Ma K, Xu D, Yu H, Wang H, et al. Clinical characteristics of 113 deceased patients with coronavirus disease 2019: retrospective study. BMJ. 2020;368:m1091.

14. Deng Y, Liu W, Liu K, Fang YY, Shang J, Zhou L, Wang K, Leng F, Wei S, Chen $L$, et al. Clinical characteristics of fatal and recovered cases of coronavirus disease 2019 in Wuhan, China: a retrospective study. Chin Med J (Engl). 2020;133(11):1261-267.

15. Wang D, Yin Y, Hu C, Liu X, Zhang X, Zhou S, Jian M, Xu H, Prowle J, Hu B, et al. Clinical course and outcome of 107 patients infected with the novel coronavirus, SARS-CoV-2, discharged from two hospitals in Wuhan, China. Crit Care. 2020;24(1):188

16. Yang $X, Y u Y, X u$ J, Shu $H$, Xia Ja, Liu H, Wu Y, Zhang L, Yu Z, Fang $M$ et al. Clinical course and outcomes of critically ill patients with SARS-CoV-2 pneumonia in Wuhan, China: a single-centered, retrospective, observational study. Lancet Respir Med. 2020;8(5):475-81.

17. Gopalakrishnan A, Mossaid A, Lo KB, Vasudevan V, McCullough PA, Rangaswami J. Fulminant Acute Kidney Injury in a Young Patient with Nove Coronavirus 2019. Cardiorenal Med. 2020;10(4):217-22.

18. Suwanwongse K, Shabarek N. Rhabdomyolysis as a Presentation of 2019 Novel Coronavirus Disease. Cureus. 2020;12(4):e7561.Suwanwongse K, Shabarek N: Rhabdomyolysis as a Presentation of 2019 Novel Coronavirus Disease. Cureus. 2020;12(4):e7561

19. Banerjee D, Popoola J, Shah S, Ster IC, Quan V, Phanish M. COVID-19 infection in kidney transplant recipients. Kidney Int. 2020;97(6):1076-82.

20. Zhou F, Yu T, Du R, Fan G, Liu Y, Liu Z, Xiang J, Wang Y, Song B, Gu X et al. Clinical course and risk factors for mortality of adult inpatients with COVID-19 in Wuhan, China: a retrospective cohort study. Lancet. 2020;395(10229):1038.

21. Wang L, He W, Yu X, Hu D, Bao M, Liu H, Zhou J, Jiang H. Coronavirus disease 2019 in elderly patients: Characteristics and prognostic factors based on 4-week follow-up. J Infect. 2020;80(6):639-45.

22. Richardson S, Hirsch JS, Narasimhan M, Crawford JM, McGinn T, Davidson KW, Barnaby DP, Becker LB, Chelico JD, Cohen SL et al. Presenting Characteristics, Comorbidities, and Outcomes Among 5700 Patients Hospitalized With COVID19 in the New York City Area. JAMA. 2020;323(20):2052-59.

23. Wang Y, Lu X, Li Y, Chen H, Chen T, Su N, Huang F, Zhou J, Zhang B, Yan F et al. Clinical Course and Outcomes of 344 Intensive Care Patients with COVID-19. Am J Respir Crit Care Med. 2020;201(11):1430-434.

24. Ruan Q, Yang K, Wang W, Jiang L, Song J. Correction to: Clinical predictors of mortality due to COVID-19 based on an analysis of data of 150 patients from Wuhan, China. Intensive Care Med. 2020;46(6):1294-297.

25. Cao J, Tu WJ, Cheng W, Yu L, Liu YK, Hu X, Liu Q: Clinical Features and Shortterm Outcomes of 102 Patients with Corona Virus Disease 2019 in Wuhan, China. Clin Infect Dis. 2020;ciaa243.

26. Eckerle I, Müller MA, Kallies S, Gotthardt DN, Drosten C. In-vitro renal epithelial cell infection reveals a viral kidney tropism as a potential mechanism for acute renal failure during Middle East Respiratory Syndrome (MERS) Coronavirus infection. Virol J. 2013:10:359.

27. Puelles VG, Lütgehetmann M, Lindenmeyer MT, Sperhake JP, Wong MN, Allweiss L, Chilla S, Heinemann A, Wanner N, Liu S, et al. Multiorgan and renal tropism of SARS-CoV-2. N Engl J Med. 2020. https://doi.org/10.1056/ NEJMc2011400.

28. Singer M. The role of mitochondrial dysfunction in sepsis-induced multiorgan failure. Virulence. 2014;5(1):66-72.

29. Ronco C, Reis T, Husain-Syed F. Management of acute kidney injury in patients with COVID-19. Lancet Respir Med. 2020;8(7):738-42.

\section{Publisher's Note}

Springer Nature remains neutral with regard to jurisdictional claims in published maps and institutional affiliations. 